\title{
Prenatal ultrasonographic findings of esophageal atresia: potential diagnostic role of the stomach shape
}

Chi-Son Chang, MD¹, Yunsun Choi, MD¹, Seo-yeon Kim, MD¹, Cheonga Yee, MD¹, Mina Kim, MD', Ji-Hee Sung, MD' ${ }^{1}$, Sanghoon Lee, MD², Suk-Joo Choi, MD, PhD', Soo-young Oh, MD, PhD', Jeong-Meen Seo, MD, PhD², Cheong-Rae Roh, MD, PhD'

${ }^{1}$ Department of Obstetrics and Gynecology, ${ }^{2}$ Division of Pediatric Surgery, Department of Surgery, Samsung Medical Center, Sungkyunkwan University School of Medicine, Seoul, Korea

\section{Objective}

We investigated prenatal sonographic characteristics of esophageal atresia (EA) with advancing gestation. We focused on the degree of polyhydramnios and the stomach shape.

\section{Methods}

This study included 27 EA cases (EA group) and 81 idiopathic polyhydramnios cases (non-EA group). The non-EA group consisted of cases without any fetal structural anomaly, musculoskeletal disorder, chromosomal abnormality, or maternal diabetes. Both groups included only singleton pregnancies. Amniotic fluid index (AFI) and width/length $(\mathrm{W} / \mathrm{L})$ ratio as well as the product of width and length $(\mathrm{W} \times \mathrm{L})$ of stomach were serially assessed during gestation and compared between the 2 groups. To predict EA using $\mathrm{W} / \mathrm{L}$ ratio and $\mathrm{W} \times \mathrm{L}$, receiver operating characteristic curve analysis was performed.

\section{Results}

Polyhydramnios was evident in $77.8 \%$ of EA cases. We observed $25.9 \%$ and $22.2 \%$ EA cases with an absent stomach and a small visible stomach, respectively. After 28 weeks, the EA group manifested significantly higher AFI than the non-EA group. After 32 weeks, W/L ratio in the EA group tended to be lower than that in the non-EA group (32-36 weeks: 1.36 vs. $1.72, P=0.092$; $>36$ weeks: 1.43 vs. $1.63, P=0.024)$. To predict $E A$, the calculated area under the curve for W/L ratio was 0.651 after 32 weeks. The diagnosis of EA using a cut-off value of W/L ratio <1.376 showed sensitivity, specificity, positive likelihood ratio, and negative likelihood ratio to be $84.6 \%, 52.9 \%, 1.796$, and 0.081 , respectively.

\section{Conclusion}

A low W/L ratio of stomach after 32 weeks with progressive idiopathic polyhydramnios may be used to predict EA.

Keywords: Esophageal atresia; Stomach shape; Polyhydramnios; Ultrasound; Prenatal diagnosis

\section{Introduction}

Esophageal atresia (EA) is a congenital malformation in which the continuity of the esophagus is interrupted. With a prevalence of 1:3,500 births, EA poses a high risk of associated anomalies, such as vertebral, gastrointestinal, cardiovascular, renal, or limb abnormalities, in 50\% cases, and 10\% EA cases are diagnosed with VACTERL association. Chromosomal anomalies are also common with a prevalence of $5-10 \%$, and most of them are trisomies $[1,2]$. Even though the survival rate in EA cases has increased to $91-98 \%$ in the last decade, mortality remains primarily related to associated
Received: 2020.07.19. Revised: 2020.10.15. Accepted: 2020.10.21. Corresponding author: Soo-young $\mathrm{Oh}, \mathrm{MD}, \mathrm{PhD}$

Department of Obstetrics and Gynecology, Samsung Medical Center, Sungkyunkwan University School of Medicine, 81 Irwonro, Gangnam-gu, Seoul 06351, Korea

E-mail: ohsymd@skku.edu

https://orcid.org/0000-0003-3002-0048

Cheong-Rae Roh has been an Editorial Board of Obstetrics \& Gynecology Science; however, he was not involved in the peer reviewer selection, evaluation, or decision process of this article. Otherwise, no other potential conflicts of interest relevant to this article was reported.

Articles published in Obstet Gynecol Sci are open-access, distributed under the terms of the Creative Commons Attribution Non-Commercial License (http://creativecommons. org/licenses/by-nc/3.0/) which permits unrestricted non-commercial use, distribution, and reproduction in any medium, provided the original work is properly cited.

Copyright $\odot 2021$ Korean Society of Obstetrics and Gynecology 


\section{Obstetrics \& Gynecology Science}

Chi-Son Chang, et al. Stomach shape in esophageal atresia

anomalies and genetic syndromes. Therefore, prenatal suspicion of EA is important [3-5].

With advancements in ultrasound imaging techniques, the detection of fetal structural abnormalities has become easier and more precise than before, but prenatal diagnosis of EA is still challenging [6]. The only known sonographic findings suggesting fetal EA are polyhydramnios with a small or invisible stomach and esophageal pouch sign $[7,8]$. In fact, in most cases with EA as well as tracheoesophageal fistula (TEF), the stomach is filled with fluid from the trachea or gastric secretion, often mimicking the normal stomach on prenatal ultrasound exam [9]. Therefore, polyhydramnios is frequently the only sign raising the suspicion of EA. However, polyhydramnios may also result from many other causes, such as maternal diabetes, other fetal structural anomalies, infection or hydrops fetalis, and neuromuscular disease; in many cases, polyhydramnios was found to be idiopathic after birth $[10,11]$. In this study, we investigated prenatal sonographic characteristics of EA with advancing gestation. We mainly focused on the degree of polyhydramnios and the stomach shape.

\section{Materials and methods}

This retrospective study included 27 EA cases (EA group) delivered at our institution between January 2007 and Octo- ber 2019. As controls, 81 idiopathic polyhydramnios cases, which were delivered during the same period and defined as cases without any fetal structural anomaly, musculoskeletal disorder, chromosomal abnormality, or maternal diabetes, were included (non-EA group). The study included inborn neonates so that their detailed prenatal sonographic data could be accessed. We included cases of idiopathic polyhydramnios in the non-EA group if polyhydramnios was observed at any time during gestation. Both the groups consisted of only singleton pregnancies.

To evaluate the changes in amniotic fluid index (AFI) and the stomach shape with advancing gestation, we subdivided gestational age into 4 categories based on the time point of ultrasound examinations (<28.0, 28.0-31.6, 32.0-35.6, $\geq 36.0$ weeks). An AFI value $>24 \mathrm{~cm}$ was considered as polyhydramnios $[12,13]$. Serial analysis of AFI in the abovementioned categories of gestational age was carried out for each patient. To determine the stomach shape, a single investigator measured the length and width of the stomach as the long shaft of stomach and the vertical line on that, respectively, using digitally saved images of standard abdominal plane for measuring abdominal circumference. The calculation of the width/length (W/L) ratio of the stomach is depicted in Fig. 1. To evaluate the size of the stomach, the product of width and length $(\mathrm{W} \times \mathrm{L})$ of the stomach was assumed as the area of the fetal stomach.
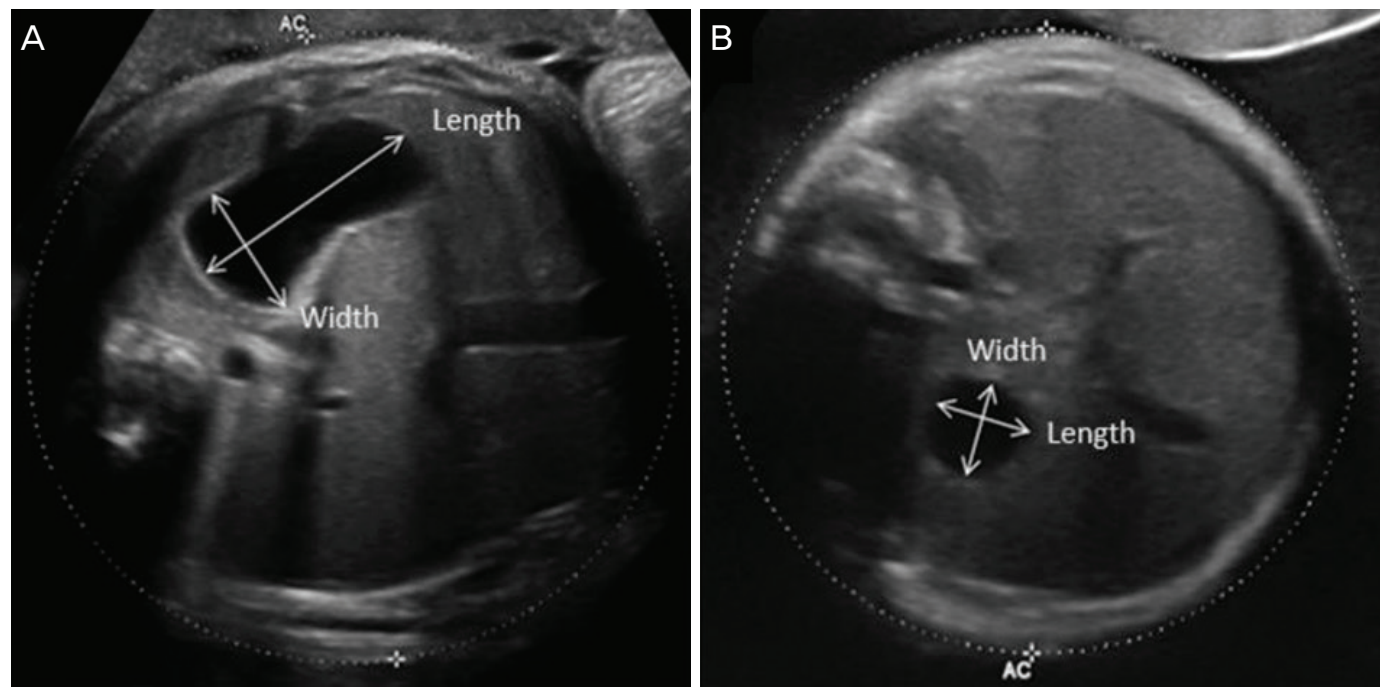

Fig. 1. Transverse plane of the fetal abdomen for measuring abdominal circumference. To determine the difference in stomach shape between esophageal atresia (EA) and non-EA cases in the presence of polyhydramnios, we calculated the width/length ratio of the stomach by measuring the width and length of the stomach from this view. The stomach of a normal fetus with idiopathic polyhydramnios (A) and the stomach of a fetus with EA (B). 


\title{
Obstetrics \& Gynecology Science
}

\author{
Vol. 64, No. 1, 2021
}

We recorded basic obstetric data including maternal age, parity, gestational age at birth, and mode of delivery. Neonatal outcomes such as sex, birth weight, Apgar score, postnatal mortality, the type of EA, and associated anomalies were collected as well. To determine the type of EA, we applied Gross classification, which is the most commonly used method, and divided EA cases into 5 different types A through $\mathrm{E}$ according to the existence and location of TEF.

Statistical analyses were performed using the Student's $t$-test or Mann-Whitney $U$ test for continuous data and the Pearson $\chi^{2}$ test or Fisher exact test for categorical data. The generalized estimating equations method was used to compare the trend of $\mathrm{AFI}, \mathrm{W} / \mathrm{L}$ ratio, and $\mathrm{W} \times \mathrm{L}$ with advancing gestation between the EA and non-EA groups. Receiver operating characteristic $(R O C)$ curve analysis was used to determine the cut-off value of $W / L$ ratio and $W \times L$ for the prediction of EA, and the area under the curve (AUC) was calculated to evaluate performance. A $P$-value $<0.05$ was considered statistically significant.

\section{Results}

A comparison of the clinical characteristics between the EA and non-EA groups is summarized in Table 1. In the EA group, preterm birth was observed in 37.0\% (10/27) cases, and $55.9 \%$ (15/27) cases were delivered by cesarean section. Compared to the non-EA group, the EA group had a lower gestational age at birth, higher preterm birth rate, and lower birth weight. Cesarean delivery rate showed no difference between the EA and non-EA groups.

Among 27 EA cases, 66.7\% (18/27) was type C EA, which is characterized by distal TEF, and $18.5 \%$ (5/27) was type A EA, which is characterized by the absence of TEF. The type of EA was not mentioned in the medical records of $14.8 \%$ (4/27) patients, but they all underwent TEF ligation surgery. Four out of 5 type A EA cases manifested an absent stomach on prenatal sonography.

Table 2 shows detailed information about the associated anomalies and sonographic findings in EA cases. Associated anomalies were observed in $81.5 \%$ of EA cases among which VACTERL syndrome and cardiac anomalies were the most common ones (22.2\%), followed by skeletal and genitourinary anomalies (11.1\%). One EA case (3.7\%) was diagnosed with CHARGE syndrome after birth. Chromosomal abnormality was found in 2 (7.4\%) EA cases, and both of them had Edward syndrome. Postnatal mortality occurred in $22.2 \%(6 / 27)$ EA cases. The specific causes of mortality were as follows: heart failure due to underlying heart anomaly $(n=4)$, respiratory failure due to tension pneumothorax $(n=1)$, and inferior vena cava tear during TEF operation $(n=1)$.

We compared neonatal outcomes in EA cases diagnosed in the prenatal $(55.6 \%, 15 / 27)$ and postpartum $(44.4 \%$, $12 / 27)$ periods. Birth weight was higher (2,454 g vs. 2,195 g, $P=0.237)$, and associated anomalies were observed less frequently in the prenatal diagnosed group (11 [73.3\%] vs.

Table 1. Comparison of clinical characteristics between the esophageal atresia (EA) and non-EA groups

\begin{tabular}{lccc}
\hline Characteristics & EA $(\mathbf{n}=\mathbf{2 7})$ & Non-EA $(\mathbf{n}=\mathbf{8 1})$ & P-value \\
\hline Obstetric & & & \\
Maternal age (yr) & $33.4 \pm 3.5$ & $33.6 \pm 3.8$ & 0.800 \\
Nulliparity & $16(59.3)$ & $39(48.1)$ & 0.317 \\
GA at birth (wk) & $37.2(31.3-40.5)$ & $38.6(29.1-41.1)$ & 0.001 \\
Preterm birth & $10(37.0)$ & $10(12.3)$ & 0.001 \\
Cesarean delivery & $15(55.9)$ & $48(59.3)$ & 0.735 \\
Neonatal & & & \\
Male & $15(55.5)$ & $46(56.8)$ & 0.911 \\
Birth weight (g) & $2,339.0 \pm 557.2$ & $3,386.0 \pm 562.7$ & $<0.001$ \\
1-min AS $<4$ & $1(3.7)$ & $1(1.2)$ & \\
5-min AS $<7$ & $1(3.7)$ & $0(0)$ & \\
\hline
\end{tabular}

Data are presented as mean \pm standard deviation, median (range), or number (\%).

GA, gestational age; AS, Apgar score 


\section{Obstetrics \& Gynecology Science}

Chi-Son Chang, et al. Stomach shape in esophageal atresia

Table 2. Associated anomalies and prenatal sonographic findings in esophageal atresia cases $(n=27)$

\begin{tabular}{|c|c|c|}
\hline Characteristics & No. (\%) & Detailed information (No.) \\
\hline \multicolumn{3}{|l|}{ Associated anomaly } \\
\hline None & $5(18.5)$ & \\
\hline Cardiac & $6(22.2)$ & $\begin{array}{l}\operatorname{VSD}(3), \operatorname{HLHS}(1), \operatorname{COA}(1) \\
\operatorname{ASD}(1)\end{array}$ \\
\hline Gastrointestinal & $1(3.7)$ & Imperforated anus (1) \\
\hline Genitourinary & $3(11.1)$ & $\begin{array}{l}\text { Pyelectasis (2), UPJ obstruction } \\
\text { (1) }\end{array}$ \\
\hline Skeletal & $3(11.1)$ & Polydactyly (2), hemivertebra (1) \\
\hline VACTERL syndrome & $6(22.2)$ & \\
\hline CHARGE syndrome & $1(3.7)$ & \\
\hline Others & $2(7.4)$ & $\mathrm{CDH}(1)$, left lung agenesis (1) \\
\hline $\begin{array}{c}\text { Chromosomal } \\
\text { abnormality }\end{array}$ & $2(7.4)$ & Trisomy 18 (2) \\
\hline \multicolumn{3}{|l|}{ Sonographic finding } \\
\hline $\begin{array}{l}\text { Polyhydramnios (+) } \\
\text { Stomach (-) }\end{array}$ & $7(25.9)$ & \\
\hline $\begin{array}{l}\text { Polyhydramnios }(+) \\
\text { Stomach }(+)\end{array}$ & $14(51.9)$ & \\
\hline $\begin{array}{l}\text { Polyhydramnios (-) } \\
\text { Stomach (-) }\end{array}$ & $0(0.0)$ & \\
\hline $\begin{array}{l}\text { Polyhydramnios (-) } \\
\text { Stomach (+) }\end{array}$ & $6(22.2)^{a)}$ & \\
\hline
\end{tabular}

VSD, ventricular septal defect; HLHS, hypoplastic left heart syndrome; CoA, coarctation of aorta; ASD, atrial septal defect; UPJ, uretero-pelvic junction; $\mathrm{CDH}$, congenital diaphragmatic hernia.

a) Two cases were complicated with preterm premature rupture of membrane, and amniotic fluid index prior to rupture of membrane was normal in both cases.

$11[91.7 \%], P=0.342)$ than those in the postpartum diagnosed group although the differences were not statistically significant. There were also no significant differences in gestational age at birth (37.2 vs. 37.2, $P=0.961)$, preterm birth rate (5 [33.3\%] vs. $5[41.7 \%], P=0.656)$, and postpartum mortality rate $(3[20.0 \%]$ vs. $3[25.0 \%], P=1.000)$ between the prenatal diagnosed and postpartum diagnosed groups.

As shown in Table 2, polyhydramnios was observed in twothirds of EA cases $(77.8 \%, 21 / 27)$, and the absence of a stomach was evident in less than half of the EA cases $(25.9 \%$, $7 / 25$ ). Polyhydramnios with a visible stomach was found in $51.9 \%$ of EA cases (14/25). There were 6 EA cases with normal AFI and a visible stomach (22.2\%); among them, 2 were complicated by preterm premature rupture of membranes.

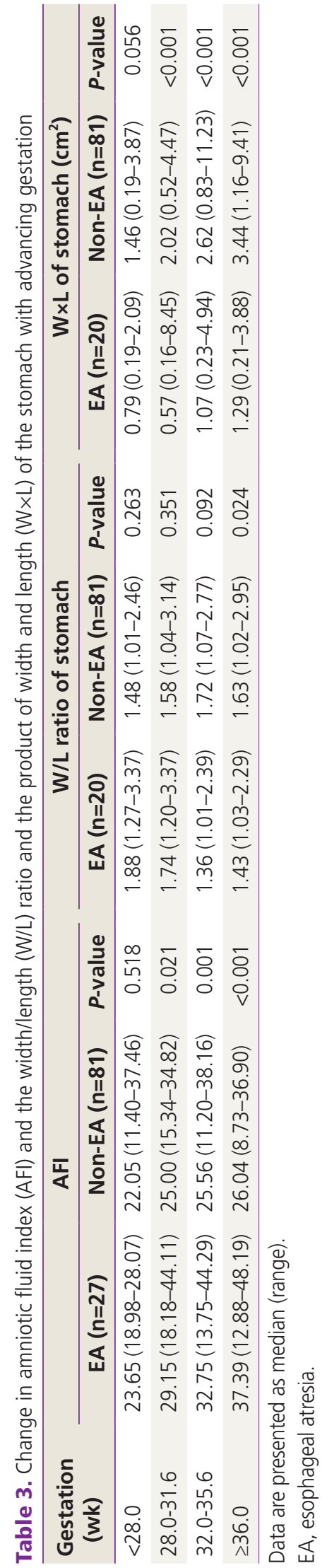




\section{Obstetrics \& Gynecology Science}

Vol. 64, No. 1, 2021
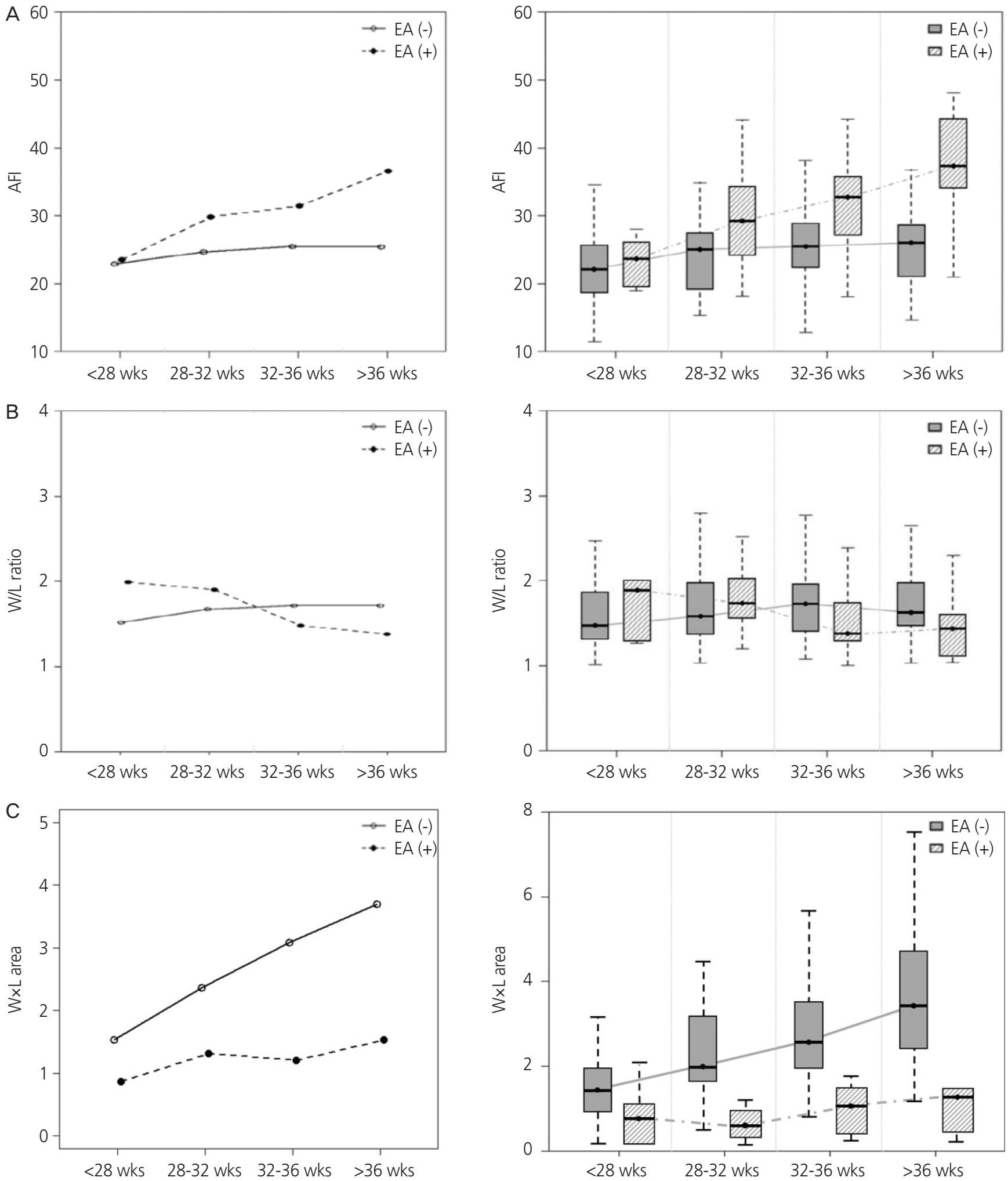

Fig. 2. (A) Mean plot and Box plot showing the trend of amniotic fluid index (AFI) with advancing gestation in the esophageal atresia (EA) and non-EA groups $(P=0.008)$. (B) Mean plot and Box plot showing the trend of stomach width/length (W/L) ratio with advancing gestation in the EA and non-EA groups $(P=0.212)$. (C) Mean plot and Box plot showing the trend of the product of width and length $(W \times L)$ of stomach with advancing gestation in the EA and non-EA groups $(P=0.010)$. 


\section{Obstetrics \& Gynecology Science}

Chi-Son Chang, et al. Stomach shape in esophageal atresia

We compared the changes in AFI, the stomach shape (expressed as W/L ratio), and the size of the stomach (expressed as $\mathrm{W} \times \mathrm{L}$ ) between the EA and non-EA groups throughout gestation. Statistical analysis of AFI showed that the AFI in the EA group was significantly higher than that in the non-EA group after 28 weeks (Table 3). As depicted in Fig. 2A, the changes in AFI in the EA group showed an uptrend with advancing gestation, while those in the non-EA group remained relatively stable $(P=0.008$, comparing trend of two groups). With advancing gestation, the W/L ratio in the EA group showed a decreasing trend (Fig. 2B). Additionally, the W/L ratio in the EA group tended to be lower than that in the non-EA group and became closer to 1 after 32 weeks of gestation, indicating that the fetal stomach in the EA group is rounder than that in the non-EA group. Table 3 also shows the median W/L ratios in the EA and non-EA groups and their changes with advancing gestation. The difference in $W / L$ ratio between the 2 groups was observed especially after 36 weeks (1.43 [1.03-2.29] vs. 1.63 [1.02-2.95], $P=0.024)$. After 28 weeks of gestation, $W \times L$

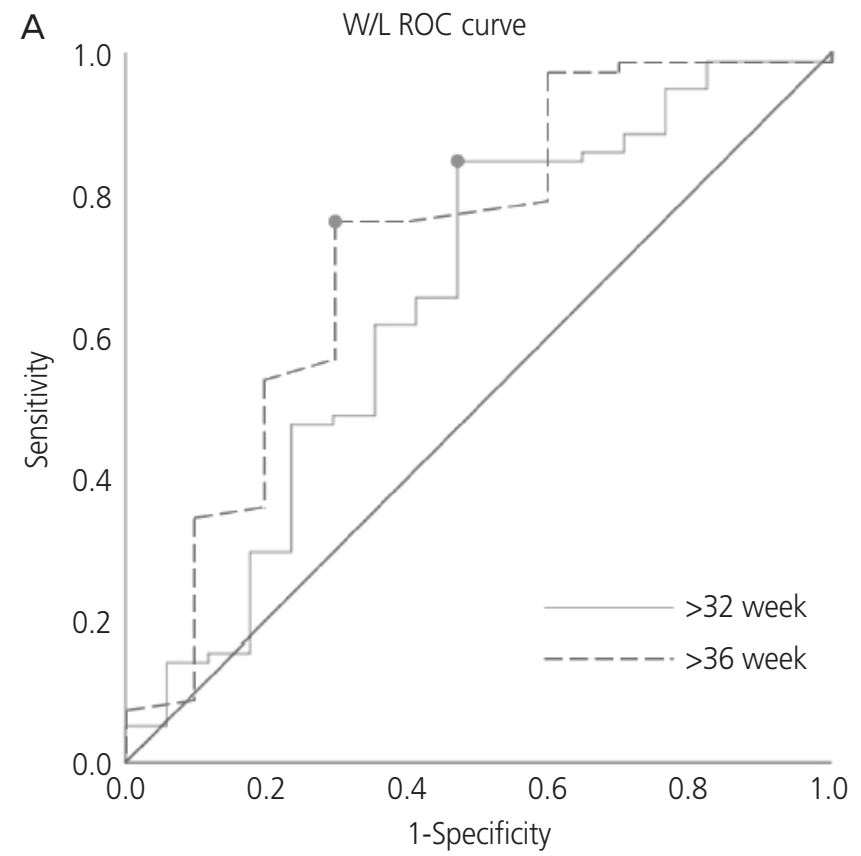

was significantly lower in the EA group than that in the nonEA group (Table 3). This finding is consistent with the previously known sonographic sign of EA, such as a small stomach bubble. Moreover, the $\mathrm{W} \times \mathrm{L}$ in the EA group remained stable, while that in the non-EA group showed an increasing trend with advancing gestation (Fig. 2C).

Finally, we performed ROC curve analysis to predict EA using $W / L$ ratio and $W \times L$ in the presence of polyhydramnios (Fig. $3 A$ and B). Overall, the AUC for W/L ratio in the presence of idiopathic polyhydramnios was 0.651 (95\% confidence interval [Cl], 0.492-0.810; $P=0.052$ ) after 32 weeks of gestation. Analyses using a cut-off value of $W / L$ ratio $<1.376$ showed the sensitivity, specificity, positive likelihood ratio $\left(\mathrm{LR}^{+}\right)$, and negative likelihood ratio $\left(\mathrm{LR}^{-}\right)$of $\mathrm{EA}$ diagnosis to be $84.6 \%, 52.9 \%, 1.796$, and 0.081 , respectively. Overall, the AUC for $\mathrm{W} / \mathrm{L}$ ratio was $0.722(95 \% \mathrm{Cl}, 0.533-0.912$; $P=0.024)$ after 36 weeks, and analyses using a cut-off value of $W / L$ ratio $<1.470$ showed the sensitivity, specificity, $L R^{+}$, and $\mathrm{LR}^{-}$of EA diagnosis to be $76.1 \%, 70.0 \%, 2.537$, and 0.341 , respectively. In addition, the AUC for $W \times L$ in the

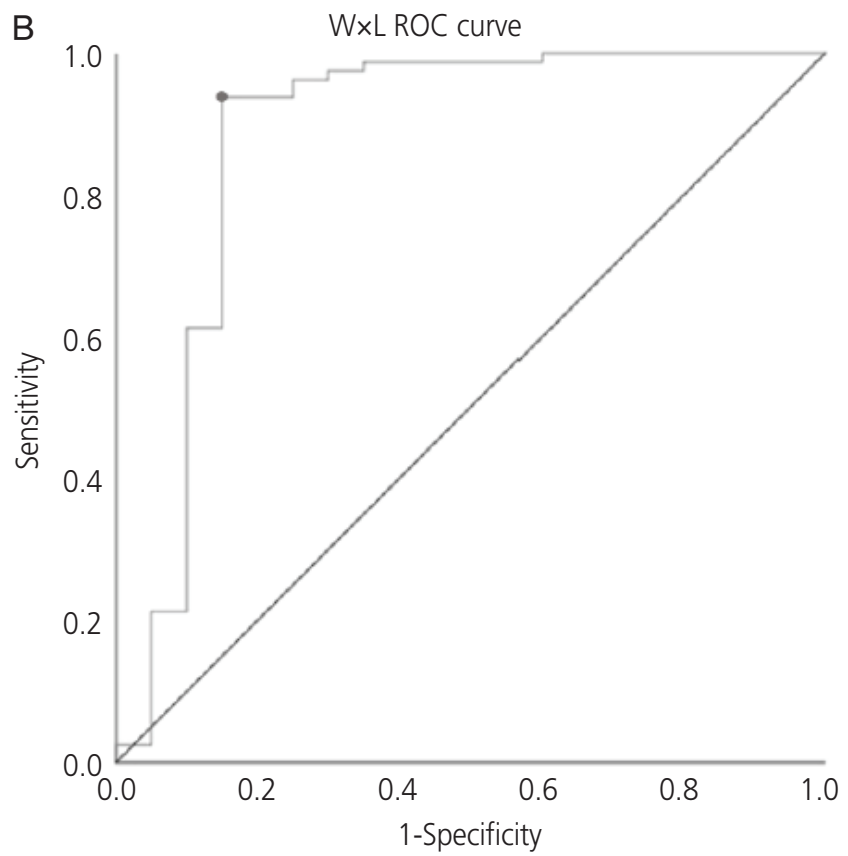

Fig. 3. (A) Receiver operating characteristic (ROC) curve with area under the curve (AUC) for stomach width/length (W/L) ratio after 32 weeks and 36 weeks of gestational age (GA) for the suspicion of esophageal atresia (EA). After 32 weeks: Cut-off value <1.376, $A U C=0.651$ (95\% confidence interval $[C I], 0.492-0.810 ; P=0.052)$. Sensitivity 0.846, specificity 0.529, positive likelihood ratio ( $\left.L^{+}\right)$1.796, negative likelihood ratio $\left(\mathrm{LR}^{-}\right)$0.081. After 36 weeks: Cut-off value $<1.470, \mathrm{AUC}=0.722(95 \% \mathrm{Cl}, 0.533-0.912 ; P=0.024)$. Sensitivity 0.761 , specificity $0.700, \mathrm{LR}^{+} 2.537, \mathrm{LR}^{-}$0.341. (B) ROC curve with AUC for the product of width and length $(\mathrm{W} \times \mathrm{L})$ of stomach after 28 weeks of GA for the suspicion of EA. Cut-off value $<1.674, A U C=0.880(95 \% \mathrm{Cl}, 0.761-0.999 ; P<0.001)$. Sensitivity 0.938, specificity $0.850, L^{+} 6.253, L^{-} 0.073$. 


\title{
Obstetrics \& Gynecology Science
}

\author{
Vol. 64, No. 1, 2021
}

presence of idiopathic polyhydramnios was $0.880(95 \% \mathrm{Cl}$, $0.761-0.999 ; P<0.001)$ after 28 weeks of gestation. Analyses using a cut-off value of $W \times L<1.674$ showed the sensitivity, specificity, $L R+$, and $L R^{-}$of EA diagnosis to be $93.8 \%$, $85.0 \%, 6.253$, and 0.073 , respectively.

Additionally, we analyzed the findings in the EA group excluding 6 EA cases without polyhydramnios as all control cases had polyhydramnios. The result was similar to that of analysis including 6 EA cases without polyhydramnios (Supplementary Table 1, Supplementary Fig. 1).

\section{Discussion}

Our study confirmed that the typical sonographic findings of EA, such as polyhydramnios with an absent stomach, are observed in only $25.9 \%$ of EA cases, whereas polyhydramnios with a visible stomach is more common (51.9\%), suggesting the importance of differential diagnosis of polyhydramnios as the sole finding in EA cases. We observed normal sonographic findings including normal AFI and stomach shape in $22.2 \%$ of EA cases. We carried out serial assessment of AFI and stomach shape throughout pregnancy in each patient rather than obtaining data from a one-time exam and compared data from the EA and non-EA groups. In pregnancies complicated with EA, AFI showed an increasing trend with advancing gestation along with prominent polyhydramnios after 28 weeks, while AFI in the non-EA group remained stable. The size of the stomach, expressed as $W \times L$, was significantly smaller and remained stable in fetuses with EA compared with that in the non-EA group. In addition, the stomach shape, expressed as W/L ratio, showed a decreasing trend with advancing gestation in fetuses with EA, especially after 32 weeks. This indicates that the stomach appears to be rounder in the EA group compared to that in the non-EA group.

When polyhydramnios is detected by ultrasound examination in the second trimester without any other structural abnormality, physicians are concerned about the possibility of a hidden anomaly. Our data implicate that the serial assessment of AFI could help in the differential diagnosis of EA in such situation, and if a progressive increase in AFI is evident even with a visible stomach, the pregnant women may need to be referred to a tertiary center under the suspicion of fetal EA. In fetuses with EA as well as distal TEF, am- niotic fluid passes through the fistula and fills the stomach. Even without a fistula, the stomach may still be fluid-filled because of secretions from the gastric mucosa [9]. These processes could make the stomach visible under ultrasound by passively ponding fluid in fetal EA. Esophageal dysmotility, which is common in patients with EA, is characterized by decreased esophageal peristalsis. It is caused mainly due to the abnormal development of esophageal smooth muscle as well as intrinsic and vagal innervation of the esophagus [14]. In this context, due to passive fluid retention via TEF or gastric secretion, the stomach shape in EA cases would be different compared to that in non-EA cases with active peristalsis.

According to a study by Kunisaki et al. [15], the prediction of EA based on an absent stomach alone had $73 \%$ sensitivity, $55 \%$ specificity, $62 \%$ positive predictive value (PPV), and $67 \%$ negative predictive value (NPV). With an absent stomach as well as polyhydramnios, better predictive values such as $91 \%$ sensitivity, $55 \%$ specificity, $67 \%$ PPV, and $86 \%$ NPV were reported. In our study, sonographic measurements of the stomach using a cut-off value of W/L ratio $<1.376$ after 32 weeks manifested high sensitivity (>80\%) and low $\mathrm{LR}^{-}$ $(<0.1)$ for identifying EA in cases with a visible stomach as well as polyhydramnios. For the prediction of EA, the AUC for $W / L$ ratio after 36 weeks was higher than that after 32 weeks. However, early suspicion of EA would be beneficial for transferring the patient to a tertiary center. Furthermore, a cut-off value of $W \times L<1.674$ after 28 weeks could be used as an objective indicator of "small stomach". We recommend a simple sonographic assessment of stomach shape as a screening test for EA due to its high sensitivity and low $L R^{-}$, especially in cases with polyhydramnios. It could be useful for both pregnant women and physicians to exclude the presence of EA.

Upon recognizing the limitations of diagnosis based on an absent stomach with polyhydramnios, which is the classical sign of EA, several studies have been conducted to identify other markers using either ultrasound or magnetic resonance imaging (MRI). Besides sonographic esophageal pouch sign in cases with polyhydramnios and/or an absent or small stomach [16], 3-dimensional ultrasonography was also demonstrated to diagnose fetal EA by Kalache et al. [17]. Recently, Ethun et al. [18] used fetal MRI for the diagnosis of EA $(n=33)$ and demonstrated $100 \%$ sensitivity of EA diagnosis based on esophageal pouch observed by fetal MRI, indicating that fetal MRI is capable of direct visual identification of 


\section{Obstetrics \& Gynecology Science}

Chi-Son Chang, et al. Stomach shape in esophageal atresia

esophageal interruption. Biochemical analyses using amniotic fluid components such as $\gamma$-glutamyl transpeptidase, alphafetoprotein, and I-leucine aminopeptidase were carried out to help the diagnosis of EA $[19,20]$.

Pardy et al. [21] performed a meta-analysis to quantify the diagnostic performance of ultrasound, MRI, and amniotic fluid analysis in detecting EA prenatally. According to their study, ultrasound alone is a poor diagnostic tool with a high false positive rate, whereas MRI and amniotic fluid analysis have high accuracy in detecting EA. However, the technical limitations and high cost of MRI are still problems for its regular use, and amniotic fluid analysis is an invasive procedure with associated interventional risks. Furthermore, the abovementioned diagnostic tools mainly focus on signs predominant in EA type A (an absent or small stomach with pouch sign), which only accounts for $7 \%$ of all EA cases $[22,23]$. In our study population, $80 \%$ of EA type A manifested an absent stomach with polyhydramnios on prenatal sonography. The most common EA type is type C (86\%); therefore, a new diagnostic marker applicable for all types of EA is necessary.

Precise diagnosis of EA during the prenatal period was thought to be clinically meaningful from the perspective of improving EA outcome by prepared neonatal management including neonatal surgery. According to Lopez et al. [5], the outcome in the high-risk EA groups between 1993 and 2004 improved compared to that during 1980 and 1992, with an increased rate of prenatal diagnosis $(94.2 \%$ vs. $90.1 \%$ in birth weight $>1,500$ g group; $75.0 \%$ vs. $63.8 \%$ in birth weight $<1,500 \mathrm{~g}$ group). On the contrary, a recent study showed that prenatal diagnosis of EA does not modify the outcome in the first year of life [24]. They reported a higher rate of postnatal complications in the prenatal diagnosis group, probably because of the high incidence of EA type $A$ or severe cases in the prenatal diagnosis subset. Prenatal diagnosis of EA is important to raise the alarm about the possibility of other malformations. It is well known that EA cases along with associated chromosomal or structural anomalies have poorer outcomes $[7,15]$. We observed postnatal mortality in $6 \mathrm{EA}$ cases $(22.2 \%)$. On the other hand, 52 outborn singletons with EA underwent immediate postnatal surgery at our institution during the study period, reflecting that the accurate prenatal diagnosis of EA is still challenging. Among them, mortality was reported in only 1 case $(1.9 \%)$ with a complex congenital heart anomaly. A significantly high mortality in the prenatal diagnosis group implies a high severity of disease or high incidence of other anomalies in these patients.

The limitation of this study is that only one operator observed and measured the fetal stomach. In addition, the W/L ratio and $\mathrm{W} \times \mathrm{L}$ of the stomach were measured based on digitally stored images and not by real-time sonographic imaging due to the retrospective nature of this study. A prospective study with multiple operators might be necessary to consider intra-observer or inter-observer variation.

In conclusion, our study suggests that the roundish shape of the stomach in the presence of progressive polyhydramnios observed during the second and third trimester may help the diagnosis of EA. Considering that the prenatal diagnosis of EA is challenging, our study contributes to improve diagnostic performance. We propose the W/L ratio and $W \times L$ of the stomach, which can be easily measured from abdominal circumference view in routine ultrasound examination, as an ancillary simple diagnostic marker for EA, especially in the presence of idiopathic polyhydramnios.

\section{Acknowledgements}

The results of this work were presented at the 29th World Congress of International Society of Ultrasound in Obstetrics and Gynecology, Berlin, Germany, October 12-16, 2019.

\section{Conflict of interest}

No potential conflict of interest relevant to this article was reported.

\section{Ethical approval}

The present study protocol was reviewed and approved by the Institutional Review Board of Samsung Medical Center (approval No. SMC2017-11-006-002) for exemption from patient's consent considering the retrospective nature of this study.

\section{Patient consent}

None. 


\section{Obstetrics \& Gynecology Science}

Vol. 64, No. 1, 2021

\section{Funding information}

None.

\section{Supplementary materials}

Supplementary materials associated with this article can be found online at https://doi.org/10.5468/ogs.20207.

\section{References}

1. Torfs CP, Curry CJ, Bateson TF. Population-based study of tracheoesophageal fistula and esophageal atresia. Teratology 1995;52:220-32.

2. Felix JF, Tibboel D, de Klein A. Chromosomal anomalies in the aetiology of oesophageal atresia and tracheooesophageal fistula. Eur J Med Genet 2007;50:163-75.

3. Koivusalo Al, Pakarinen MP, Rintala RJ. Modern outcomes of oesophageal atresia: single centre experience over the last twenty years. J Pediatr Surg 2013;48:297303.

4. Deurloo JA, Ekkelkamp S, Schoorl M, Heij HA, Aronson DC. Esophageal atresia: historical evolution of management and results in 371 patients. Ann Thorac Surg 2002;73:267-72.

5. Lopez PJ, Keys C, Pierro A, Drake DP, Kiely EM, Curry JI, et al. Oesophageal atresia: improved outcome in highrisk groups? J Pediatr Surg 2006;41:331-4.

6. Bricker L, Garcia J, Henderson J, Mugford M, Neilson J, Roberts $T$, et al. Ultrasound screening in pregnancy: a systematic review of the clinical effectiveness, costeffectiveness and women's views. Health Technol Assess 2000;4:i-vi, 1-193.

7. Stringer MD, McKenna KM, Goldstein RB, Filly RA, Adzick NS, Harrison MR. Prenatal diagnosis of esophageal atresia. J Pediatr Surg 1995;30:1258-63.

8. Kalache KD, Wauer R, Mau H, Chaoui R, Bollmann R. Prognostic significance of the pouch sign in fetuses with prenatally diagnosed esophageal atresia. Am J Obstet Gynecol 2000;182:978-81.

9. Sparey C, Robson SC. Oesophageal atresia. Prenat Diagn 2000;20:251-3.

10. Hamza A, Herr D, Solomayer EF, Meyberg-Solomayer G.
Polyhydramnios: causes, diagnosis and therapy. Geburtshilfe Frauenheilkd 2013;73:1241-6.

11. Smith CV, Plambeck RD, Rayburn WF, Albaugh KJ. Relation of mild idiopathic polyhydramnios to perinatal outcome. Obstet Gynecol 1992;79:387-9.

12. Yefet E, Daniel-Spiegel E. Outcomes from polyhydramnios with normal ultrasound. Pediatrics 2016;137:e20151948.

13. Sandlin AT, Chauhan SP, Magann EF. Clinical relevance of sonographically estimated amniotic fluid volume: polyhydramnios. J Ultrasound Med 2013;32:851-63.

14. Faure C, Righini Grunder F. Dysmotility in esophageal atresia: pathophysiology, characterization, and treatment. Front Pediatr 2017;5:130.

15. Kunisaki SM, Bruch SW, Hirschl RB, Mychaliska GB, Treadwell MC, Coran AG. The diagnosis of fetal esophageal atresia and its implications on perinatal outcome. Pediatr Surg Int 2014;30:971-7.

16. Shulman A, Mazkereth R, Zalel Y, Kuint J, Lipitz S, Avigad I, et al. Prenatal identification of esophageal atresia: the role of ultrasonography for evaluation of functional anatomy. Prenat Diagn 2002;22:669-74.

17. Kalache KD, Bamberg C, Proquitté $H$, Sarioglu N, Lebek $H$, Esser T. Three-dimensional multi-slice view: new prospects for evaluation of congenital anomalies in the fetus. J Ultrasound Med 2006;25:1041-9.

18. Ethun CG, Fallon SC, Cassady Cl, Mehollin-Ray AR, Olutoye OO, Zamora IJ, et al. Fetal MRI improves diagnostic accuracy in patients referred to a fetal center for suspected esophageal atresia. J Pediatr Surg 2014;49:712-5.

19. Muller C, Czerkiewicz I, Guimiot F, Dreux S, Salomon $\sqcup$, Khen-Dunlop N, et al. Specific biochemical amniotic fluid pattern of fetal isolated esophageal atresia. Pediatr Res 2013;74:601-5.

20. Czerkiewicz I, Dreux S, Beckmezian A, Benachi A, Salomon LJ, Schmitz T, et al. Biochemical amniotic fluid pattern for prenatal diagnosis of esophageal atresia. Pediatr Res 2011;70:199-202.

21. Pardy C, D'Antonio F, Khalil A, Giuliani S. Prenatal detection of esophageal atresia: a systematic review and meta-analysis. Acta Obstet Gynecol Scand 2019;98:68999.

22. Spaggiari E, Faure G, Rousseau V, Sonigo P, MillischerBellaiche $A E$, Kermorvant-Duchemin $E$, et al. Performance of prenatal diagnosis in esophageal atresia. Pre- 


\section{Obstetrics \& Gynecology Science}

Chi-Son Chang, et al. Stomach shape in esophageal atresia

nat Diagn 2015;35:888-93.

23. Bradshaw CJ, Thakkar H, Knutzen L, Marsh R, Pacilli M, Impey $L$, et al. Accuracy of prenatal detection of tracheoesophageal fistula and oesophageal atresia. J Pediatr Surg 2016;51:1268-72.
24. Garabedian C, Sfeir R, Langlois C, Bonnard A, KhenDunlop N, Gelas T, et al. Does prenatal diagnosis modify neonatal treatment and early outcome of children with esophageal atresia? Am J Obstet Gynecol 2015;212:340. e1-7. 